\title{
Improving Interaction in Online Liaison Services through Skype
}

\author{
Peace Ossom Williamson, University of Texas at Arlington, Arlington, TX, USA
}

\begin{abstract}
This article describes a pilot project of enhanced virtual reference services through a multifaceted model of services that includes the addition of Skype reference. The project was created as a response to a growing need for advanced liaison services to the College of Nursing at The University of Texas at Arlington, which predominantly consists of online students. The number of online nursing students and degree and certificate programs offered by the university has grown exponentially in current and previous years, making this a particularly significant case study. Detailing of the method used to respond to user needs and of the outcome of the project will further the conversation about supporting online student success.
\end{abstract}

Keywords: $\quad$ AcademicLibraries, Chat Reference, DistanceEducation, Embedded Librarianship, Multifaceted Reference Model, Nursing, Online Learning, Outreach, Text Reference

\section{INTRODUCTION}

Online student learning has increased from 1.6 million students in 2002 to more than 7.1 million undergraduate and graduate students who took one or more online classes in 2012 (Allen \& Seaman, 2014), and this trend continues as an increasing number of learning objects migrate to the online environment. In response, academic libraries are evaluating and adapting their services to suit distance students' needs. Chat, phone, and text reference services - in combination with teaching and learning through LibGuides and digital learning objects—often assist students who are in need of quick and straight-forward information, and these services have largely been adapted from in-person services already existing in libraries. While these efforts have worked to improve online assistance, it is greatly advantageous for libraries to determine user needs in the online or virtual environment and subsequently create services to fill those needs. Providing multifaceted services based upon new models of reference assistance that consider the experience of the online student can improve liaison librarians' effectiveness in assisting distance students.

\section{University of Texas at Arlington}

More specifically, at The University of Texas at Arlington (UT Arlington), online education is a prime focus. UT Arlington is a growing research institution centered between Dallas and Ft. Worth in Texas. It is the second largest student body in The University of Texas System, only 
trailing The University of Texas in Austin. It also consists of a very diverse student body: It is tied with five other institutions as the fifth most diverse university in the United States (U.S. News, 2013). Although UT Arlington is developing into a residential campus from a commuter campus, its more than 33,000 students are either from or located in every state in the U.S. and 120 other countries, and more than 11,000 of these students take online courses (The University of Texas at Arlington, 2014). The online course offerings of the College of Nursing have drastically increased, as have the number of online students, and its students make up one fourth of the university population along with the overwhelming majority of online students; thus, an effort to better serve these students was crucial for UT Arlington Libraries.

\section{UT Arlington Libraries}

The mission of UT Arlington Libraries' is to foster and promote Knowledge Creation, idea eXploration, and learning Innovation (CXI), and this is put into action by focusing its initiatives on values including its services, flexibility, and community. This mission largely drives the nearly 20,000 reference transactions and 700 instruction sessions completed each year (The University of Texas at Arlington Libraries, 2014). In accordance with this mission, the Libraries' Department of Outreach and Scholarship has three subgroups: Science, Technology, Engineering, and Math (STEM); Social Sciences; and Arts and Humanities. These groups consist of full time liaisons who serve the various departments on campus. In addition to these often-called core or primary liaisons, librarians in most of the other departments also serve liaison roles as dual liaisons. This allows for a varying number of liaisons serving departments, depending largely on the department's size and the department's needs. In service to the College of Nursing, the UT Arlington Libraries' STEM Outreach and Scholarship department head developed a team of four nursing liaison librarians. One librarian is a full time liaison, while the other three are dual liaisons with their primary responsibilities being in other departments. These librarians have offered several supplemental services to improve the experience of distance students. This effort includes increased chat reference offerings and availability and includes Skype consultations. Also, local research had been completed on the role of LibGuides in learning, and the librarians updated the nursing subject, topic, and course guides using this evidence of teaching and learning.

The liaison services and the subsequent experiences at UT Arlington serve as a preliminary framework for developing a multifaceted model of service that pays particular attention to the needs of distance students. This article will utilize this framework in discussing the role of liaison expertise and job function in the general structure and division of library services. The discussion will be further augmented by an explanation of the multifaceted model, as well as an illustration of the outcomes of the pilot project at UT Arlington.

\section{BACKGROUND}

\section{User Preferences and Characteristics}

There have been drastic changes in the ways that people obtain information, and many describe this age as a time of information renaissance. Information is conveniently at a user's fingertips in the sense that a quick search in a search engine will usually provide them with all of the information they need. According to the principle of least effort, referred to in both psychology and in library and information science fields, most individuals seek the method of accomplishing an act that has the least amount of barriers; therefore, a particular method of information-seeking highly values convenience over other attributes, such as accuracy or consistency (Bierbaum, 
1990; Colman, 2008). As research has transitioned to an online environment, searching efficiency has become the predictor of success in the realm of search products. For example, Google is well-known for its clusters, or a categorization process that enables a search engine in retrieving relevant results for a vague and simple search query. Because of this strength, it has remained the most preferred and most frequently used search engine for much longer than any other search engine had before it. Herbert A. Simon coined the term satisficing to describe searching at a basic level until a result suffices, rather than a more optimal method of decision making (1957). As libraries are drastically renovating and revamping the services they provide in order to adapt to the current information renaissance culture, they are being affected by information abounding in many formats and by the fact that users have little loyalty to any one source of information or assistance. Over $56 \%$ of libraries have virtual library services in addition to digital collections, and these services are increasing exponentially each year (Chow, Bridges, \& Commander, n.d.). This shift in focus from library collections to library services is largely due to dwindling circulation statistics and increasing information needs, the proliferation of databases and other technologies, and the larger variety of research methods now more commonly available to students. Moreover, these students have less contact with professors and instructors than did previous generations.

As libraries continue to introduce a variety of services in the attempt to adapt to changing user needs, more information will arise as to which services are useful and in which situations these services are successful. In recent years, libraries have added new services only to quickly discontinue them due to low use, and there is an assortment of reasons as to why these services fail. These reasons can include the institutional background, the budget, the audience, or the marketing of a service, and whether students are aware of its existence and its purpose (Atlas, 2005; Mu, Dimitroff, Jordan, \& Burclaff, 2011). Of greatest influence is the perception of users. Many library users have preferred methods of communication and adhere strictly to these communication methods. Many times, they will only use one or two methods exclusively. In a recent study of user behavior, face-to-face reference assistance was used most often, or $49 \%$ of the time, while email was second in use at $36 \%$ (Chow \& Croxton, 2012). When asking respondents about their preferred virtual method of communication, multiple studies have found that users chose chat and email most often, and respondents of these studies reasoned that these methods were most convenient due to their already being familiar with them (Chow \& Croxton, 2012; Luo \& Pomerantz, 2005; Radford, Connaway, Pomerantz, Mon, \& Janes, 2008). This familiarity and convenience translated for them into greater perceived ease of use than the other methods. In addition, the respondents of various studies reported chat and text to be highly preferred over email or videoconferencing services due to cost, convenience and immediacy, access and efficacy, and anonymity (Chow \& Croxton, 2012; Desai, 2003; Luo \& Pomerantz, 2005; Radford et al., 2008). Chow and Croxton (2012) also found that patrons valued response time most highly, followed by ease of use and the ability to multitask; however, when questioned, respondents generally replied that they had not ever used any or most of these services.

In contrast to the responses found in these studies, students and faculty members largely value subject knowledge and expertise, but they are not willing to wait long for responses as is the nature of asynchronous communication like email (Connaway, Dickey, \& Radford, 2011). Therefore, the theory behind this program is one which focuses on the user's specific situation, in that different services are suitable for different users. One important characteristic is a user's preferred contact method; however, a user's information need must also play a determining role in the services available, especially for distance students. The team of four nursing liaison librarians serving the College of Nursing have introduced or improved services geared toward creating a better experience for in person and distance students, and the online offerings are based on research into the online experience in learning. Researchers in education have heavily 
emphasized a sense of presence in online teaching and learning because humans crave interaction through shared awareness, immediacy, and space (Kehrwald, 2008); consequently, instructors are increasingly focused on redesigning online courses to accommodate for this shared experience.

Distance is not the only factor that is important to consider: The average online student at UT Arlington is an adult learner (30 to 44 years old). Various research studies and surveys have emphasized that educators should focus on the adult learner's personal anticipation, uncertainty, and anxiety (Ausburn, 2004; Booth, 2009; Cubeta, Travers, \& Sheckley, 2001; Holborn, Savas, Ward, \& Hudson, 1995; Knowles, 2007). Adult learners are different from the average learner because they still prefer email communication but fear seeking help from their younger classmates or from a librarian. In a recent study, adult learners mentioned several reasons against reaching out for help, such as being able to figure things out on their own, being off campus or far from campus, and needing help from librarians later at night (Ismail, 2013). Notably, previous contact and familiarity were major influences on students as to whether they contact a librarian for help, and this was especially more of a factor for students 40 years or older (Ismail, 2013). Librarians should also be aware of their libraries' online sense of presence and engage students in a way that improves familiarity, and this differs from a Facebook page or a website because it must involve those shared experiences to resonate with students and better serve their needs.

\section{Existing Reference Models}

Models or theories about online reference service have recently begun to develop and progress. The DELOS Libraries Reference Model was created by the DELOS Network of Excellence on Digital Libraries. This group was formed in January 2004 and partially funded by the European Commission to provide research and direction for a new infrastructure in digital libraries (DELOS Network of Excellence on Digital Libraries, n.d.). The DELOS model determines that the digital library framework is guided by six core concepts: content, user, functionality, quality, policy, and architecture (Candela et al., 2007). The reference model is more abstract in nature and considers best practices and research to account for the market, motivations, requirements, and goals of its users (2007). The reference model then guides the reference architecture, which considers factors like standards and specifications to account for the same market and motivations as the reference model (2007). This model works to show compliance through explicit benchmarks; however, it is general enough to be adapted to a wide variety of online library services. In addition, the focus on the purpose of services in formation of a delivery method can provide the framework for librarians in determining decisions and processes for expanding, restricting, or adapting services.

The 5S Model describes the digital library through five fundamentals: streams, structures, spaces, scenarios, and societies (Isah, Mutshewa, Serema, \& Kenosi, 2013). A stream is any transfer of information (e.g., video or text), and a structure is organization (e.g., taxonomies or workflows) (2013). Space can be a physical or virtual environment, scenarios are the ways in which users encounter the library or its services, and societies are the relationships formed between components or between persons (2013). This model is similar to the DELOS Libraries Reference Model in that it involves a consideration of the small parts that come from general intentions and the ways these small parts interact with each other to create scenarios-and, ultimately, societies - that describe user interaction with library services and structure. The $5 \mathrm{~S}$ Model is much more detailed in description and framework than the DELOS Libraries Reference Model; however, they both inform general frameworks for creating or cultivating meaningful services. 


\section{MULTIFACETED REFERENCE MODEL}

According to the Association of College and Research Libraries Standards for Distance Learning Library Services, "Library services offered to the distance learning community must be designed to meet a wide range of...user needs and should provide some form of direct user access to library personnel" (2008, Services section, para. 1). It goes on to say that services will vary by institution (2008). This notion of flexibility is also reflected in the OASIS Reference Model for Service Oriented Architecture (SOA), which states, "A Reference Model consists of a minimal set of unifying concepts, axioms and relationships within a particular problem domain, and is independent of specific standards, technologies, implementations, or other concrete details" (MacKenzie, Laskey, McCabe, Brown, \& Metz, 2006, p. 4).

Upon incorporating prior research into study of these guidelines, the author created a multifaceted model of reference in service to the unique needs of the UT Arlington nursing student body. There was a need for a more precise model that built upon the preexisting DELOS Library Reference Model, OASIS SOA Reference Model, and the 5S Model because of the varied user types existing within one library system. The Multifaceted Reference Model centers on reference service, and more specifically to liaison work and outreach assignments. When developing a reference model specific to a library, especially a larger library, the author took consideration of patterns in common and uncommon reference interactions occurring in the library as well as common issues and concerns being expressed by students. The model generalizes these interactions into three reference types which are hierarchal but overlap in definition. It is also common for students to progress through the three levels of reference as they formulate their questions or materialize problems they have been encountering due to a lack of knowledge about whom to seek for the solution. The solution of one issue can greatly influence users' likelihood of returning to the liaison librarian for assistance with another issue. According to the Multifaceted Reference Model, the three levels of reference — quick, in-depth, and comprehensive - operate on a continuum and can often occur in unmethodical order. There is, however, a great amount of discrepancy in the occurrence of the three reference types, as shown in Figure 1.

\section{Quick Reference}

The first type, quick reference, is a reference interaction generally less than 10 minutes in duration. Questions that the librarian receives and answers very often are great examples of quick reference. For distance students, these can include course or textbook information, basic citation concerns, or instructions on finding an article's full text. The best method of providing quick reference services is through the use of text message and chat reference and through answering questions from incoming phone calls to the reference desk, to the service desk, or to liaison's office phone. Generally, most library employees will have the ability to answer these questions, with the exception of those who work in cataloging, technical services, or systems departments. Students' strong preference for immediate assistance is dependent upon a strong structure and support for quick reference services in the library. Structures include availability on chat and text reference and library operating hours. They also include the speed and dependability of the technology that supports these services. In addition, the nature of the interactions or scenarios in which students interact with library employees or with library systems can also affect their reuse of these systems and services. Locally, the Ask a Librarian service at UT Arlington is being streamlined, and the librarians are being provided with guidelines for posting answers into the public FAQs knowledgebase. As an example, providing a link to a website with the answer is largely unsatisfying for students, and they have made that known through low scoring of answer 
Figure 1. Components of the Multifaceted Reference Model. This figure illustrates the quantity of reference interactions at the three levels and the methods of providing these services. In a comprehensive reference phone consultation, there must be additional support, usually through simultaneously working on a computer or on a document.

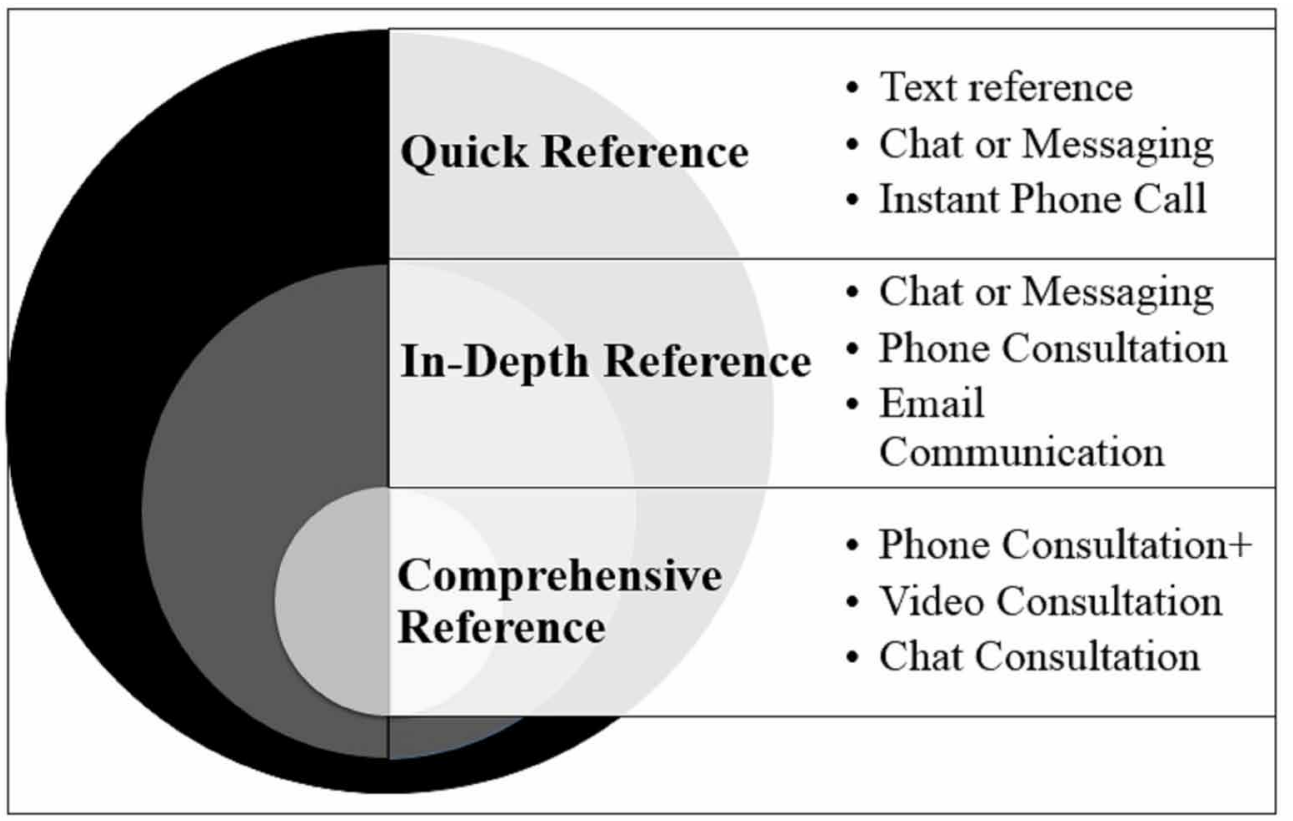

entries in the knowledgebase that only provide a link. In response, librarians are creating more robust and self-sufficient entries by providing concise and numbered steps that answer the question while providing supporting links to relevant webpages. Libraries' awareness of their quality in quick reference services can lead to an increase in in-depth reference service interactions.

\section{In-Depth Reference}

The second type of reference, in-depth reference, is generally between 10 and 30 minutes and involves a more personalized response. In-depth reference occurs much less often than quick reference, but it requires greater knowledge of subject matter. Some student and part-time employees can sometimes be less equipped to manage these reference questions because of fewer opportunities to encounter them and subsequent unfamiliarity with the databases, discovery systems, or other technologies used to provide in-depth reference assistance. Library employees who are both familiar with common reference questions and comfortable with being explanatory in nature through distance communication means are best at providing in-depth reference services to distance students. In-depth reference can be similar to quick reference, which is generally on the spot and allows for little to no prior preparation. In addition, in-depth reference can be a compilation of many quick-reference questions. This often occurs when a student who has been avoiding or creating temporary solutions for issues he or she has been facing comes to or is sent to a library employee with a particular question. The student then seeks guidance on the issues he or she has been struggling to overcome due to being unaware of the librarian's ability to correct those issues. These issues can include technology problems that result from either a library 
program or from its interaction with the student's software or settings. These issues can also result from more traditional reference concerns, including the need for assistance in choosing a research paper topic, an introduction to databases, and uncommon or numerous citation concerns.

As the concepts of in-depth reference become more specialized, library employees with other responsibilities can provide students with referrals to liaisons who can schedule consultations with those students. Students looking for best practice or benchmark articles centering on a particular population with a specific medical condition are largely referred from library staff to the nursing liaison librarians. Communication methods of in-depth reference should not involve text message services, except when used for scheduling. Lengthy chat reference assistance and continuous email correspondences, while beneficial and well suited for in-depth reference services, are best avoided in situations that involve an excessive amount of explanation for the librarian, lengthy procedures for the student, or complicated instructions. Chat reference and email reference, however, work well when a librarian is sending a compilation of resources or a quick answer that involved extensive research on the part of the librarian. Lengthy phone consultations are also a primary component of in-depth reference services. In cases where the conversation is not going smoothly, adding supplemental assistance-e.g., emailed screenshots or search strategies and links to LibGuides and webpages - can greatly improve the student's satisfaction with the consultation and awareness of available information resources.

\section{Comprehensive Reference}

Ultimately, if it is difficult to engage in teaching and learning through the previous methods of consultation, the final type of reference services, comprehensive reference, may be beneficial. These consultations generally include a variety of reference questions and some element of instruction. Comprehensive reference is titled as such because it makes use of the broadest variety of technologies and answers a wide range of questions within one consultation and is usually supplemented with messages through email and other forms of communication. Similarly to in-depth reference, comprehensive reference can encompass an amalgamation of the other two types of assistance. What sets it apart is a need for much more detailed assistance. This can be greatly hindered when using quick reference services like chat reference. Strengthening comprehensive reference was the major focus in service to UT Arlington nursing students, as many of these students struggle with technology and research and feel they have little support near Arlington and across the country.

\section{VIRTUAL REFERENCE SERVICES}

Academic librarians quickly adapted to web technologies; services like email and chat, in addition to already existing phone services, were welcomed by the library community for providing better availability of library staff to students and faculty. While virtual reference vendors offer programs that varied greatly in cost and features, LibChat is one of the most commonly used chat reference programs in academic libraries. The benefit of LibChat is its ability to offer real-time assistance in addition to an easy to use interface and assessment capabilities. Students taking online courses are more likely to need reference assistance at less traditional times of the day, and Springshare's knowledgebase of frequently asked questions (FAQs) can accommodate those needs. While not virtual reference in itself, FAQs can improve students' experience coupled with traditional virtual reference services, including chat. These services offered in a comprehensive collection, allow librarians to discuss topics with students, sending and receiving replies. Librarians are also able to share links, images, and documents and keep track of the conversations that took place within 
the program. Because many are now familiar with online chat services, offered by a variety of organizations, companies, and institutions for reporting and troubleshooting problems, instituting the service in libraries has met little to no resistance. Many prefer this method of communication as it involves timely and efficient service in addition to the option of anonymity. Its use in virtual reference services allows librarians to reach students instantaneously at their time of need with little geographical restrictions or restrictions on device types.

\section{General Reference Services}

UT Arlington Libraries' virtual reference and consultation offerings are very similar to other academic libraries across the United States and in various other countries. These services were instituted in the early 2000s, and the adoption of virtual reference services at UT Arlington has largely been welcomed by the student, faculty, and administrative community. Recently, library staff have instituted more changes to adapt to the trends in student needs at this rapidly growing research institution. UT Arlington Libraries' employees engaged in various task forces and ethnographic studies in preparation for a major reorganization that took place in the summer of 2013. The reorganization occurred simultaneously with an update of library services and was instituted to allow for major changes, including the adaptation of individuals' job duties to ones better suited to their talents, skills, and passions. Out of 112 total employees, 106 of the libraries' employees received new titles under the reorganization. Many of the employees underwent complete job changes, while others had more minor changes in their job duties. A major component of this reorganization was also the renaming and restructuring of different departments. Reference services had originally been provided by the Reference Department. After the reorganization, they are largely the responsibility of the User Engagement Services (UES) Department. UES also provides circulation assistance and student outreach. This is a newly developed department, and reference services within this department come from both librarians and paraprofessionals, both of whom are skilled in working with databases and technology. UES is a department whose employees work the consolidated service desks in the Central Library, the Science and Engineering Library, and the Architecture and Fine Arts Library. The circulation and reference assistance offered by the UES Department is in person, via text, chat, or Ask a Librarian submissions using LibChat and LibAnswers, two integrated Springshare products. Reference questions were also answered by phone or through an email listserv. All library staff receives the listserv email requests, but UES staff generally responds to these requests.

Other departments were created during the reorganization, including the Department of Outreach and Scholarship. This department consists of 11 liaison librarians working with the various colleges and departments across the university to provide instruction and specialized consultations. Liaisons also work to promote scholarly communication and digital humanities, to collaborate with faculty and students within and across disciplines, and to promote various library services and resources to students and faculty. In addition to these core liaisons, 27 dual liaisons also offer approximately $20 \%$ of their time in assistance to students and faculty. Liaisons spend an average of three to five hours working at the consolidated service desks in the three libraries, and also engage in regular virtual reference assistance through LibAnswers and LibChat. Library employees - usually UES staff - refer students and faculty to liaison librarians for more complicated or specialized information, creating a tiered service. Liaisons also receive direct contact from students and faculty through email or phone and respond in kind with answers or more information.

Like the liaisons, other library employees also tend to respond to questions through the original method that contact was made. Liaisons, however, are more likely to adapt communication by 
evaluation during the reference interview. In situations where the original contact method cannot accommodate the student's need, liaisons will determine the best method of communication. At that point they suggest a consultation and either conduct the consultation at that moment or schedule a consultation at the earliest time possible. Consultations generally occur in person or over the phone. The limited options for liaisons in offering extensive virtual reference can greatly hinder their ability to assist students.

\section{Problems for Nursing Students}

As of May 2014, the almost 10,000 online students within the College of Nursing made up about $75 \%$ of the online students in the University. In addition, about $45 \%$ of the online students are undergraduate students between 30 and 40 years of age. Each year, the number of programs and the number of students are increasing drastically; therefore, it was important for the nursing librarians to be aware of the particular needs of these students. The online programs largely consist of non-traditional students because these programs offer flexibility for people returning to school, people with families, or people with full time jobs or other responsibilities outside of the classroom. These students have different needs than traditional students, as they tend to have less experience with technology, including databases, learning management systems, and other web technologies. This can also lead to apprehension. UT Arlington nursing liaisons often interact with students who are struggling with the technology aspect of completing their degrees. This can manifest itself in searching for appropriate scholarly articles on their given topic or their topic of choice. They often mention having spent countless hours over several days attempting to research a topic and not being able to find anything or finding too many articles that are not on their intended topic. In addition to struggling with when to search on the open web versus the library catalog or discovery system, or when and how to search in databases, students often struggle with difficulty connecting to these resources in addition to using tools like citation managers.

Often, conversations attempting to correct issues students are having with web resources and tools can be extremely inefficient when using chat reference, email, or phone consultations. There are several reasons for this. One reason is the failure of technology in consistency. LibChat can often disconnect the student unexpectedly from the chat conversation the student is having with a librarian or library employee. This can occur regularly to one student, causing the student to become dissatisfied with the service and unwilling to use it again. Technology interruption can also occur via phone when the call disconnects unexpectedly or via email, where email messages are delayed. This occurs rarely but can sour students' experience with the library. Another reason that traditional virtual reference communication methods can be inefficient is the aforementioned issues with asynchronous emails. Many students work for long periods of time attempting to fix their issue without seeking help, and, once they do, it is with little time to spare. Waiting for a clear and carefully drafted email response can take too much time for these students, and the answer may come too late. Finally, in cases where complicated or numerous steps must be completed, it can be difficult for librarians to explain these steps in enough detail for the student to understand. It often takes excessive amounts of time to attempt to do something as simple as getting on the same webpage as the student, and this can cause dissatisfaction on both the part of the student and the librarian. 


\section{PILOT PROGRAM SERVICES}

In response to student needs, the nursing librarians instituted a number of activities in support of in-person and online students. The liaisons spent four days per week embedded in the building housing the College of Nursing. They were located in the lobby of the Nursing Learning Resource Center (LRC), a center with various resources for students, including simulation equipment, study rooms, text books, and instructors. As the librarians sat at the front, they were providing reference assistance to students as they studied or worked on projects together. Many students also purposefully sought nursing librarians during their advertised times in the LRC because of its convenience and their busy schedules. Nursing librarians also offered services for online and in-person students alike by using web 2.0 technologies. These services were provided according to the multifaceted model of reference. One such service was through nursing chat widgets. These are small chat boxes created using LibChat functionality. After a LibChat administrator customizes a chat widget, LibChat provides the code to be copied. The code for the nursing chat widget was placed online where students often visit-e.g., the Nursing Subject LibGuide. All four of the nursing librarians are connected to the nursing chat widgets; so, it would show chat as available any time one or more nursing librarians were logged into the system and showing as online. This service increased nursing librarians' offerings and availability online and gave students a greater confidence in the assistance they received as they knew they would be reaching a liaison with expertise in their particular subject. The structure of the library LibGuides were also evaluated by a taskforce of librarians. This taskforce determined that the LibGuides were confusing to the average user due to the overabundance of links to resources (Trkay, Herzog, Bailey, Mirza, \& Huddleston, 2013). This taskforce also determined that LibGuides can be highly valuable through the use of instruction and information literacy standards informing students of the steps to take, rather than just a list of resources to use (2013). With this evidence of LibGuides as a teaching tool that could be adapted according to usage assessment (2013), the content within the LibGuides was updated to address common coursework and frequently asked questions. Quick-reference questions were generally answered through the media they were received, and links to the LibGuides created with generally helpful content would be provided as supplemental instructions for common questions. Library staff would then refer students to the LibGuides when necessary. Because LibChat is web-based and has no limit on the number of concurrent users, librarians can log in from anywhere instead of having to be at a specified computer or having to download specific software. This feature is beneficial in allowing librarians to be available at nontraditional times more often. LibChat also provides information about where chat questions originate - e.g., through one of the widgets or through the library general chat - and it allows users to choose which chat widgets to make available.

Quick and in-depth reference questions often come through chat reference or through emailed questions. Because nursing students make up the majority of questions through chat reference, the liaisons assigned to the College of Nursing make themselves available via the group chat widget any time they are not in a meeting or working on a project involving a great amount of concentration and focus. This chat widget has improved the overall quality of answers being given to nursing students in chat because a larger percentage of these questions are being answered by subject librarians. The chat widget also increases the amount of regular visitors and the length of visitors' stay on the LibGuide. 


\section{Skype Consultation Services}

Most notably, the addition of Skype consultations has assisted in reference and consultation services for the College of Nursing. In order to provide assistance via Skype, the Libraries' administration approved the purchase of a high definition camera with built-in microphone. The camera operates on the latest technology in web videoconferencing, and it is made to synch directly with Skype. With Skype, there is no cost to sharing screens. In order to share screens simultaneously with video, there is a $\$ 9.99$ per month charge for a Premium account. ${ }^{1}$ Because faculty for distance education courses in the College of Nursing have their office hours and student consultations through Skype, many students already have an account and the program downloaded on their computer. There have been students who do not already have prior experience with Skype. In this case, they often benefit from an email with my username and a short instructional video on installing Skype. The final instruction, if they are still unable to download it, was to tell them that they can have a family member download the program for them, allowing them to use it throughout their studies and share screens and communicate visually. However, this situation has not yet occurred; students have been able to download the needed software without many problems.

The Skype sessions began as one of the components of service to distance students in the fall 2014 semester, and usage increased steadily over the course of the semester. Because the camera is located in the office of the core nursing liaison, it was not operated by the dual liaisons. The core librarian's specific duties and availability were largely created and operated individually and independently. Students were more often referred to Skype sessions after contacting the nursing librarian by phone or by email. Although questions that could be answered in one email were completed in kind, the nursing librarian was much more likely to recommend Skype sessions when a particular student was making repetitive contact with the librarian, receiving responses, and still having trouble. The recommendation was similar for phone contact, but it differed slightly. In many instances, a phone consultation became derailed by the inability of the librarian and student in synching their webpages. Either the librarian or student would be directing the other to a particular page for the purpose of identifying the problem on the student's end or for the purpose of instruction on the librarian's end. Verbally describing screens completely unfamiliar to the other individual in this process became lengthy and inefficient, leading to the librarian's recommendation of a Skype appointment. Because there is more opportunity for repeated contact and response within one phone conversation, the librarian was more comfortable recommending Skype consultations during the initial phone call.

All Skype sessions were set up using appointments. The only on-the-spot Skype conversations occurred after a scheduled and completed Skype appointment, and these came through direct contact from the student's Skype account. Students were given a short set of directions that asked them to contact the librarian at their scheduled appointment time and were given the librarian's Skype handle. The librarian defaulted to this instruction to allow students to followthrough with the appointment only if they needed it. In two circumstances, the students no longer needed assistance from the librarian. One of those students contacted her during their scheduled time nonetheless because she wanted to thank her for a previous Skype consultation, which had highly benefited her and her study group in ultimately finding the research they needed for their paper. The other student did not make contact. Students, in all cases but one, were able to quickly and easily contact the librarian through her Skype account. In the one case where the student was having difficulty, she had been able to set up an account but was unable to make the call. In that case, the librarian initiated the student consultation through Skype. 
Surprisingly, the students were welcoming of Skype consultations, and only one student engaged in a Skype consultation that did not use the videoconferencing feature. Although there are many advantages of the video feature, Skype is multidimensional in the various combinations of features that can be used during a call or conversation. Video calls, audio only calls, screen sharing, instant messaging, and the delivery of links and documents can all be used in concert. In this case, instant messaging differs from the chat features of LibChat because users must have an account and contact one another directly. With instant messaging, students also were able to leave messages with the librarian, even when she was signed off of her Skype account. With library chat, there is no control over whom students are contacting, and there is no ability of the student to leave quick messages when the librarian is logged out of chat. Users can also choose which features to use, which adapts the service to the individual, and the instant messaging feature was often used as a supplement to consultations or as a means of communication between calls. Most often, the Skype consultations included video calls and screen sharing; some also included sharing documents, links, or screenshots. Two students also left voice messages on the librarian's Skype account when she was unavailable. This voice messaging service was of more benefit than telephone voice mail for both the librarian and the student because it offered the librarian the ability to check it anywhere. While Skype voice messages automatically sent a notification email to the librarian, who could then check it anywhere she had internet access, the librarian was only able to received telephoned voice messages in her office phone when she was there, and they did not come with any notification.

Skype consultations centered on either or both of the following topics: research assistance and technology assistance. In the first case, students were looking to find resources for research papers, and were having trouble coming up with a useful topic or were having trouble finding supporting resources. Often, the librarian would walk the student through the Nursing Subject LibGuide, which provided information on finding or creating a topic and on finding resources. The student would ask questions as the librarian described research steps. In many of the cases where students were coming up with their topic, the librarian would describe the PICO process of creating a clinical question. This involves identifying the Population or Problem to be addressed and the Intervention and a possible Comparison intervention working toward a specific Outcome (PICO). Students would download the PICO worksheet from the nursing subject guide, and the student would work on identifying a more accurate topic with the assistance of the librarian. After the student was equipped with a topic that was appropriately precise or general, depending on the assignment, the student and librarian would work together to conduct broad database searches and then use limiters to improve precision based upon results.

In the second case of Skype consultations, students were struggling with their connection to library resources and databases off campus or in use of RefWorks citation manager services, including Write-N-Site. These consultations were highly technical, and, in many cases, the librarian had to seek the advice of the Office of Information Technology (OIT) staff and the librarians in the Library Systems and Technology Department. The librarian would screen share, and the student would walk her through the steps she took to get to the problem. Even when the librarian was unable to duplicate the problem, she was aware of the steps taken that led to it. With this knowledge, she was more aware of what could be causing the issue. Some issues confronted during Skype sessions were the interference of Mozilla Firefox, Internet Explorer, and Google Chrome browser settings in the use of RefWorks web-based tools; issues with the connection to the library's proxy server due to students' internet service provider (ISP) limitations; and errors in Microsoft Word citation tools. However, not all issues were caused by technical failures or disconnects. Some issues, like going through the library website to access databases or full text or directions for using citation export tools and citation manger in-text and reference citation 
tools, were easily addressed through walking through the steps with which students were struggling. Skype consultations generally seemed of most benefit to these particular student needs, and the outcomes were generally positive for improving student learning and for increasing student satisfaction and self-efficacy.

\section{OUTCOMES}

\section{Improved Learning through Practice}

Skype allowed for better comprehensive reference assistance by simulating in-person interaction with distance students. Skype consultations are only appropriate for this type of reference assistance because it involves more preparation for the student than does chat or email, which is generally ready to use at any moment without downloading or purchasing any specific software or hardware. Skype is beneficial for students because it is a more viable alternative to in-person assistance than other methods of interaction. It is exceedingly difficult to engage in a comprehensive reference consultation with a distance student through the phone, especially if they are having challenges technologically. Its screen sharing capabilities allow for hands-on instruction that is more typical of in-person reference assistance.

Students generally do not share their screens because it would require they pay a fee, but this has not been something that has negatively affected the consultations. There is no real need for it because students can walk the librarian through the steps they took that led them to their problem when "co-sharing" the librarian's screen. In searching databases, it also allows the librarian to search along with the student, using different search strategies, to find various ways in searching for articles. This is highly beneficial as it becomes more of a team effort, where the librarian and student are working together and practicing researching skills, rather than the student passively receiving the knowledge of the librarian. In these cases, students often provide the librarian with key words that are working or terms that are restricting their results. Students often benefit from this in the long run as they are using the skills they practiced during the Skype sessions rather than simply duplicating a search given them by the librarian.

This has also shown a greater benefit for the students involved than do screencasts. Screencasts are videos of screen activities coupled with recorded audio instruction or voiced information. While screen casting is very beneficial for providing general instructions and bring dynamism to LibGuides, they are not adapted to individual users who may need more information in one area or less information in another. In addition, while the librarian is in screen sharing, the student can build those tactile skills during the learning process. Furthermore, this can become much more highly involved than any other interaction because students are in a more comfortable place. They are generally at home on their own personal computer and feel much more at ease with trying several searches with varying levels of success without worrying about their privacy. There may be more concerns with unsuccessful searches for students in the library or more motivation to quickly finish using a computer that is not their own. Also, students are able to keep those windows open and continue searching after the consultation is over or easily transfer these references into a paper because they are using their own personal device. While screen casting is viable in online teaching, screen sharing through programs like Skype can provide more meaningful interactions with longer lasting retention. 


\section{Increased Satisfaction through Interaction}

Generally, students who have reached out for comprehensive reference assistance are much more likely to prefer synchronous communication. This communication is limited in many ways for distance students, for students who work, for students with children or other family obligations, or for students with any major responsibilities outside of their educations. Skype allows these students communication through more than just written language. Speech patterns, emphasis on certain words, and interjections assist in communication. Also, for those face-to-face sessions, body language enhances communication and connection. This is especially important as many students report feeling lost or alone in their studies and feel that they have little support. Often, students who begin their sessions feeling sad, upset, or angry quickly become more cheerful and feel more empowered in their research through Skype conversations than they do during conversations over the phone. Moreover, Skype sessions tend to last much longer than phone sessions or in-person sessions because students are simultaneously getting assistance as well as engaging in hands-on learning; Skype provides an avenue for students to work hands-on with their liaison and feel more comfortable with silences because of their ability to see one another typing, writing, or engaging in other types of work. This ability to see the librarian working interacts with their use of their own computers. They are much more likely than in-person students to begin searching on their own computers simultaneously with the librarian. These experiences are beneficial for future recall and self-efficacy. Further assessment of this service over the next several semesters may lead to expanding the service to other liaisons.

\section{LOOKING FORWARD}

As education continues to migrate to the virtual environment, it is crucial for libraries to be finely in-tune with the needs of its constituents. According to a recent IMLS and OCLC funded study (2014) using qualitative and quantitative data from surveys, telephone and focus group interviews, and chat transcripts, users and librarians value various experiences in virtual reference (see Figure 2). The multifaceted model of reference services can be used to address these views by offering convenient and efficient responses to quick reference and most in-depth reference questions. Accuracy coupled with a positive attitude and good communication skills should be present in all interactions, regardless of information need level. Skype consultations are especially well suited to these needs as they cultivate students' relationships and comfort with their librarian and his or her services. Furthermore, it assists librarians' effort in providing their complex and specialized knowledge through clear synchronous communication. In these conversations, students can ask questions as they go and steer the conversation toward the information they need, thus improving student attitudes and increasing opportunities for feedback and response. This activity also improves the librarian's relationships with these students.

As virtual reference services develop and multiply, coupling evidence and theory will provide more successful programs adapted specifically to the online library users. Currently, reference interviews are also being conducted in the online environment, and users are finding their interactions during these consultations as favorable. Looking ahead, librarians should not rely on these responses but should instead continuously work toward increasing the presence of these services while improving efficiency and efficacy of reference responses. A Skype consultation service is a starting place in providing assistance on the spot. It is adaptable in its ability to address a plethora of user concerns and creates an environment where librarians can adjust to their responses in the moment to consultation instruction. Testing the multifaceted model of reference 
Figure 2. OCLC research. Two views of what's effective in VR experiences. Slideshare, http:// www.slideshare.net/oclcr/connaway-uc3-m-vrs-evaluation-16-may-2014-final-35803023.

\section{Two Views of What's Effective in VR Experiences}

Users:

- Convenience

- Comfort with service

- Accuracy

- Positive attitude

- Good communication skills

- Relationships with librarians
Librarians:

- Ability to leverage complex \& specialized knowledge

- Positive attitudes, responses, \& feedback

- VR tools \& hybrid communication modes

- Relationships with users

\section{QocLC Resesarch}

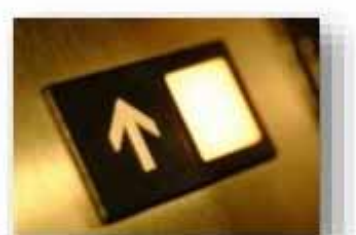

in a number of libraries can show its effectiveness across differing situations. Expanding upon the model by addressing the technology needs associated with common question types may also create more opportunities for libraries to update their virtual reference services. Currently, Skype consultations lend themselves well to consultations about researching a topic and finding articles and consultations about technology issues; however, there may be more uses for these consultations that have yet to be explored on this campus, for various reasons. There may be more of an overwhelming need for answers to these types of questions for UT Arlington nursing students in comparison with students at another campus or with students at another institution. Likewise, there may be reference needs that are more prominent in other institutions that UT Arlington Libraries are less likely to encounter. Furthermore, research comparing the use of supplemental Skype consultations with the traditional modes of virtual reference can work to show its impact. Qualitative assessment, such as students' level of satisfaction with the interaction, and quantitative assessment, such as marked improvement in student grades, can contribute to libraries' facilitation and marketing of these services and to increasing the value of the library within the institution. Studies should also consider integrating research about students' use of ISPs and the effect it has on their ability to use the various services being offered. Librarians' are more compelled to consider and institute some form of assessment, and this trend is likely to increase with assessment measures being more proven and explicit. 
Librarians are also more involved in search engine optimization and analyzing usability and user behavior on websites. One major contributor to the success of the multifaceted reference assistance was the use of LibGuides as elements of teaching. They are well-formatted and include video, screen shots, and other elements contributing toward learning that users can continue to use well after their chat or consultation sessions. Moreover, the location of links to use services like Ask a Librarian, chat reference, email, and other methods of contact can make a significant difference in the number of inquiries a library will receive. Librarians are at the forefront of encouraging and improving current online patterns of behavior, and these changes can move the profession into a role that is highly esteemed in higher education.

As librarians transition, particular focus on the new prominent user needs can augment the effects of these changes. It was once the librarian's role to be the keeper of information, willing and ready to provide answers on a moment's notice. While that role is not completely eliminated, there is a greater focus in libraries on instruction. The librarian's new prominent role is to be the guide or the instructor leading users on a path toward greater information literacy. The information is now at the fingertips of each user, so, instead of providing it, librarians must facilitate proven and effective methods toward access. This does not simply include navigation of databases, catalogs and discovery systems; this also involves awareness of technology's role in access. Device variability and the provision of the Internet through different methods, including 4G and Wi-Fi or Wireless Local Area Networks (WLAN) and the interaction of these technologies with library websites and resources can greatly influence student use and satisfaction with the library in general and with virtual reference, more specifically.

UT Arlington Libraries' other developments also center on providing a number of experts in various areas that relate to the questions being received that are not specifically traditional reference. Circulation and reference have already been combined in student assistance services, but information technology, writing, and other services generally spread across campus are being incorporated in an academic food court, centering all helpful resources in the hub of the university, the Central Library. There are also librarians who specialize in digital humanities and data needs, especially as they relate to scholarly communications. These librarians are liaisons on their own but also consult across disciplines to better serve students and faculty in their output. As learning continues online, students and faculty are expressing the need for this support more than previously, and services are adapting to this growing need. Other research in UT Arlington Libraries related to serving online students' needs include increasing the number of synchronous experiences through the use of robots. The library currently has a robot that is currently being tested for this purpose, and the purchase of more robots may be a potential assessment project. The current library robot can be operated through an app that can be downloaded on various devices and allow distance users to "attend" events in real time. Users can control the movements of the robots, including the adjustment of its height and focus, as well as the ability to move it around a room. Through the robot, users can engage in conversations and have a presence without the limitation to a stagnant monitor or laptop screen. In addition, a user has more control over the robots' features as they decide where the robot stays or moves to and with whom to speak, rather than someone present at the event placing the monitor in one location and determining when to use videoconferencing technology to connect that user.

Technology is allowing libraries to make major initiatives in the services that they provide to online and distance students, but libraries must remember to market and publicize these new and exciting services. The average individual has little to no knowledge of the vast array of services and resources being offered by modern libraries, and it is difficult for many people to see libraries differently than a place to read books or to find traditional forms of reference assistance. UT Arlington Libraries recently instituted a Department of Marketing and Communications during 
the reorganization, and the director of this department manages the Libraries' contact with local, regional, and national news outlets. She also communicates regular news about the libraries with all of the colleges and departments on campus. This department also creates advertising materials, including signs and posters, which are distributed across campus and to members of the community. These materials also promote new and ongoing services and programs being offered by the UT Arlington library staff. Marketing and communication is a field that has conducted a great amount of research, and librarians can work to change the perspective of academics about the libraries through evidence-based methods.

\section{CONCLUSION}

Online student learning is a trend that shows no sign of slowing in the near future. In fact, the rates of online students are increasing at a rapid pace. Virtual reference services, such as chat, email, and text, in combination with LibGuides and digital learning objects, currently dominate the learning environment. These have shown great efficacy, but librarians must center their services on evidence-based models of reference. Providing multifaceted services that account for the online user's experience will adapt libraries to the new landscape in learning. Convenience and accuracy are the key elements to most reference transactions, but libraries can benefit from recognizing the diverse reference levels and the elements most crucial to each. Students value librarians' subject expertise and the relationships they have with these subject experts. Having a sense of presence is a need particular to online education, and this can be facilitated in a number of ways.

Organization of services can assist librarians in incorporating a sense of presence with other factors, such as speed and accuracy. Existing models of reference-e.g., the DELOS Libraries Reference Model and the 5S Model-largely focus on the technological structure of access and discovery, and this largely promotes organization in access to online resources, library websites, and discovery systems; however, more organization can be done through a multifaceted reference model. This model organizes the methods of direct access to library subject experts. The hierarchal quick, in-depth, and comprehensive reference levels pertain to common reference interactions and are delineated from one another according to the time a librarian takes in assisting that user and its technology needs. Services like LibChat and LibAnswers are beneficial in addressing those quick reference needs and allow librarians to provide timely and accurate information. Extended email and phone conversations can provide a balance between timeliness and completeness for in-depth reference, and videoconferencing software, such as Skype, allow for a more fluid and continuous communication that can address several complicated research and technological problems. LibChat and LibAnswers questions are largely similar across disciplines, so the consolidation of general reference and circulation assistance is beneficial for quick responses, while more subject-specific questions can be addressed by their subject librarian.

Although this model is effective, there are times where attempts to address student concerns with web resources, tools, and technology can be hindered by the limitations of chat, email, or phone services due to dropped chat conversations, the inability to see what the other is doing, and the chat and email limitations on writing messages that are too long. In cases where complicated or numerous steps must be completed, it can be difficult for librarians to explain these steps in enough detail for the student to understand, and simple tasks often take excessive explanation. In response, library administration urges staff to seek methods of providing service that may be nontraditional but uniquely meet the needs of students. The pilot projects put into place by the core and dual liaisons to the College of Nursing followed a multifaceted frame of reference by 
providing convenience, accessibility, and expertise through the various services offered to inperson and online students. Because the College of Nursing comprises the vast majority of UT Arlington's online student community and its fastest growing population, services that benefit this group can greatly improve the visibility and impact of UT Arlington Libraries on campus.

Embedded librarianship and nursing chat widgets coupled with user-centered LibGuides and analogous digital learning objects increase the availability of nursing librarians to the entire College of Nursing student body. In addition, Skype consultations offered by the core nursing liaison created an avenue for more comprehensive reference assistance. In many cases, students were more comfortable with their librarian and made vastly greater contact with the librarian following their first Skype consultation. In addition, half of the students who had a Skype consultation requested a second at another point in their research. Although early researchers of Skype reference assistance talk about students discomfort with video calls, there was only one student who did not engage in the video call feature. This is likely due to increasing contact and communication in general. The trend may be increasing people's comfort with having conversations over the web than they had felt in the past.

The content of these conversations largely centered either on research, technology, or both. While faculty members largely reach out to the core liaison about topics relating to scholarly communication, copyright, and online teaching, students overwhelmingly had questions about research methods and using new research technologies. The positive outcomes of these consultations were that students were more comfortable practicing their newly-acquired skills and were more comfortable with "co-searching," which became a collaborative effort between student and librarian. For privacy reasons, screen sharing was completed every time by the librarian and not by the student. This enabled students to describe the steps they took to the problems they are having without having to translate what they are seeing on their screen with the librarian, as they would have had it been a phone or email conversation. In addition, the librarian and students were able to share documents, images, and links with one another.

In addition to the positive learning outcomes, students were very satisfied with their Skype sessions and often expressed their shock with how beneficial it was for them. Not only were the consultations beneficial in providing information, but the librarian was also able to provide a broader context of library services, websites, and resources. Furthermore, students were able to get a larger understanding of the research and writing process, which increased their comfort with their assignment parameters. Ultimately, students benefited because these sessions often created a deeper relationship with their librarian, and the students who engaged in Skype sessions contacted the librarian regularly afterwards.

As technological advances promote more diverse ways of promulgating information with larger groups, librarians must find the methods that are best suited for promoting their services and adapting these services to this ever-changing environment. The "forever beta" slogan must be adopted by libraries, in that resting into the methods we have always used and resisting any change will ensure our extinction. Virtual reference gives librarians the opportunity to reach new groups we would have otherwise never reached, and the focus on synchronous real-time assistance should be present. Programs like Skype have no associated fee, so it is easier than ever for libraries to test new products and services with their students. The days are nearing when libraries no longer have to endlessly research and debate the addition of a new feature. The mentality of failing fast will become more commonplace, making rapid change more accepted. When institutions attempt various methods, it can either lead to useful information or a discovery. Virtual reference is inherently flexible in adaptation of responsiveness, so constant attempt and evaluation can direct libraries to better ways of serving their patrons. 
Overall, it is most beneficial for liaison librarians to offer multifaceted support in order to maximize opportunities for instruction. As more students attend schools virtually, an increasing number of in-depth and comprehensive reference questions will be coming to librarians virtually. It is best to be able to provide assistance that can focus on the topic at hand, rather than communication barriers. Skype can be one of the tools to improve communication with distance students or with students who cannot often come to the library, as it allows for screen sharing capabilities and improves modes of communication to be more than just word usage or audio. Other resources that improve students' relationship with and subsequent use of their librarian are modern technologies that take the in-person experience and provide it to online students. Students who feel the sense of presence and sense of belonging can become libraries' strongest and most convincing allies.

\section{REFERENCES}

Allen, I. E., \& Seaman, J. R. (2014). Grade change: Tracking online education in the United States. Babson Survey Research Group, LLC.

Association of College \& Research Libraries. (2008). Standards for distance learning library services. Retrieved from http://www.ala.org/acrl/standards/guidelinesdistancelearning

Atlas, M. C. (2005). Library anxiety in the electronic era, or why won't anybody talk to me anymore? Reference and User Services Quarterly, 44(4), 314-319. Retrieved from http://www.jstor.org/stable/20864407

Ausburn, L. J. (2004). Course design elements most valued by adult learners in blended online education environments: An American Perspective, 41(4), 327-337. Retrieved from https://www.uwec.edu/AcadAff/ resources/edtech/upload/CourseDesignElementsMostValuedByAdultLearners.pdf

Bierbaum, E. G. (1990). A paradigm for the '90s. American Libraries, 21(1), 18-19. Retrieved from http:// www.americanlibrariesmagazine.org/

Booth, C. (2009). Informing innovation: Tracking student interest in emerging library technologies at Ohio University. Chicago, IL: Association of College and Research Libraries, American Library Association.

Candela, L., Castelli, D., Pagano, P., Thanos, C., Ioannidis, Y., Koutrika, G., \& Schuldt, H. et al. (2007). Setting the foundations of digital libraries: The DELOS manifesto. DELOS Network of Excellence on Digital Libraries, 13(3/4). doi:10.1045/march2007-castelli

Chow, A., Bridges, M., \& Commander, P. (n. d.). What is a usable library website? Results from a nationwide study [PowerPoint]. Retrieved from http://lisuncg.net/wp-content/uploads/uploaded_photos/2010/11/ michelle_bridges_patricia_commander_poster.pptx

Chow, A. S., \& Croxton, R. A. (2012). Information-seeking behavior and reference medium preferences. Reference and User Services Quarterly, 51(3), 246-262. Retrieved from http://rusa.metapress.com/content/ r335811g7x1p0645/fulltext.pdf doi:10.5860/rusq.51n3.246

Colman, A. M. (2008). Principle of least effort. In A dictionary of psychology (p. 583). New York: Oxford University Press.

Connaway, L. S., Dickey, T. J., \& Radford, M. L. (2011). "If it is too inconvenient I'm not going after it:" Convenience as a critical factor in information-seeking behaviors. Library \& Information Science Research, 33(3), 179-190. doi:10.1016/j.lisr.2010.12.002

Cubeta, J., Travers, N. L., \& Sheckley, B. G. (2001). Predicting the academic success of adults from diverse populations. Journal of College Student Retention, 2(4), 295-311. doi:10.2190/E9JJ-Q2GG-9RHN-N588

DELOS Network of Excellence on Digital Libraries. (n. d.). About DELOS. Retrieved from http://www. delos.info/index.php?option=com_content\&task=view\&id=299\&Itemid=26 
Desai. (2003). Instant messaging reference: How does it compare? The Electronic Library, 21(1), 21-30. doi: $10.1108 / 02640470310462380$

Gonçalves, M. A., Fox, E. A., Watson, L. T., \& Kipp, N. A. (2004). Streams, structures, spaces, scenarios, societies (5S): A formal model for digital libraries. ACM Transactions on Information Systems, 22(2), 270-312. doi:10.1145/984321.984325

Holborn, R., Savas, A., Ward, A., \& Hudson, L. (1995). Support services for adult learners enrolled in distance education courses. Journal of Education Media \& Library Sciences, 32(3), 387. Retrieved from http://joemls.dils.tku.edu.tw/fulltext/32/32-4/378-387.pdf

Isah, A., Mutshewa, A., Serema, B. C., \& Kenosi, L. (2013). Digital libraries: Analysis of DELOS Reference Model and 5S Theory. Journal of Information Science Theory and Practice, 1(4), 38-47. doi:10.1633/ JISTaP.2013.1.4.3

Ismail, L. (2013). Closing the gap. Reference and User Services Quarterly, 53(2), 164-173. doi:10.5860/ rusq. $53 \mathrm{n} 2.164$

Kehrwald, B. (2008). Understanding social presence in text-based online learning environments. Distance Education, 29(1), 89-106. doi:10.1080/01587910802004860

Knowles, A. J. (2007). Pedagogical and policy challenges in implementing E-learning in social work education. Journal of Technology in Human Services, 25(1-2), 17-44. doi:10.1300/J017v25n01_02

Luo, L., \& Pomerantz, J. (2005). Motivations and uses: An evaluation of users' use of a chat reference service. Proceedings of the American Society for Information Science and Technology, 42(1). doi:10.1002/ meet. 14504201137

MacKenzie, C. M., Laskey, K., McCabe, F., Brown, P. F., \& Metz, Rebekah (Eds.), (2006). Reference model for service oriented architecture 1.0. OASIS Committee Specification, 1(2). Retrieved from https:// www.oasis-open.org/committees/download.php/19679/soa-r

Mu, X., Dimitroff, A., Jordan, J., \& Burclaff, N. (2011). A survey and empirical study of virtual reference service in academic libraries. Journal of Academic Librarianship, 37(2), 120-129. doi:10.1016/j. acalib.2011.02.003

OCLC Research. (2014). Two views of what's effective in VR experiences [PowerPoint]. Using virtual reference services to embed the library in the academic workflow (pp. 26). Retrieved from http://www. slideshare.net/oclcr/connaway-uc3-m-vrs-evaluation-16-may-2014-final-35803023

Radford, M. L., Connaway, L. S., Pomerantz, J., Mon, L., \& Janes, J. (2008). E-valuating e-reference: Transforming digital reference through research and evaluation. Proceedings of the American Society for Information Science and Technology, 45(1), 1-11. doi:10.1002/meet.2008.1450450123

Ritterbush, J. (2014). Assessing academic library services to distance learners: A literature review of perspectives from librarians, students, and faculty. The Reference Librarian, 55(1), 26-36. doi:10.1080/027 63877.2014 .853274

Simon, H. A. (1957). Administrative behavior: A study of decision-making processes in administrative organization (2nd ed.). New York: Macmillan.

Trkay, G., Herzog, A., Bailey, J., Mirza, R., \& Huddleston, B. (2013). Plugged into user behavior: Lowbudget, high-impact usability testing of library subject guides. Pre-conference presented at Association of College and Research Libraries. Indianapolis: ACRL.

The University of Texas at Arlington. (2014). Website. Retrieved from http://www.uta.edu

The University of Texas at Arlington Libraries. (2014). Library vision and values. Retrieved from http:// library.uta.edu/library-vision-and-values

U.S. News. (2013). Campus ethnic diversity rankings. Retrieved from http://colleges.usnews.rankingsandreviews.com/best-colleges/rankings/national-universities/campus-ethnic-diversity/ 